\title{
Occurence and Toxicity Assessment of Polycyclic Aromatic Hydrocarbons (PAHs) in Mangrove Soil of Dong Rui area, Vietnam
}

\author{
Ms. Do Thi Lan Chi \\ Lecturers \\ Dept of Occupational health and Safety \\ Trade Union University, \\ Hanoi, Vietnam
}

\author{
Ms. Nguyen Thi Thu Hien \\ Researcher \\ Dept of Environment \\ Institute of Environmental Science and Technology- \\ Hanoi University of Science and Technology \\ Hanoi, Vietnam
}

\begin{abstract}
An evaluation of the polycyclic aromatic hydrocarbons (PAHs) contamination in the mangrove soil from Dong Rui area, Vietnam was carried out. Twelve representative soil samples were collected in July 2016. The analyzed results indicated the wide occurrence of contamination of PAHs in Dong Rui. In sampling sites along BaChe River, total concentrations of $\Sigma 16$ PAHs ranged from 522.1 to $1405.1 \mu \mathrm{g} \mathrm{kg}-1 \mathrm{dw}$ (from DR1 to DR4, mean $881.7 \pm 392.1 \mu \mathrm{g} \mathrm{kg-1} \mathrm{dw),} \mathrm{while} \mathrm{those} \mathrm{along} \mathrm{Voi} \mathrm{Lon}$ River and Voi Be River ranged from 432.5 to $1873.4 \mu \mathrm{gg}-1 \mathrm{dw}$ (from DR5 to DR12, mean $928.4 \pm 523.2 \mu \mathrm{g} \mathrm{kg-1} \mathrm{dw).} \mathrm{The} \mathrm{total}$ toxic equivalence (TEQ) value of PAHs in the soil samples from Dong Rui range from 52.2 to $310.3 \mu \mathrm{g}$ TEQ $\mathrm{kg}-1 \mathrm{dw}$. The values of ecological risk quotient (RQ) of BaP ranged from 1.98 to 13.71 whereas those of other RQ were less than 1 . Due to the propensity of PAHs to accumulate in various compartments of environment, further evaluation of ecotoxicological should be undertaken as a high priority.
\end{abstract}

Keywords: PAHs; mangrove soil; toxic equivalence; ecological risk quotient.

\section{INTRODUCTION}

Polycyclic Aromatic Hydrocarbons (PAHs) are contained in the group of persistent organics; since they have high toxicity and ability to bioaccumulate, they can result in pollution with long-term effects on the human body and the environment. The main sources of PAHs are from industrial waste (thermal power plant), transport (combustion of fuels such as gasoline and oil), and daily activities (combustion of coal and wood...). PAHs are also present in the components of petroleum and thus, can also penetrate into the environmental components in case of oil leaks or oil spills. A number of PAHs are capable of causing cancer and dominant gene mutation; in addition, they can exist with considerable concentration in the environment. According to the classification of the U.S Environmental Protection Agency, there are 16 typical PAH including: naphthalene (Nap), acenaphthylene (Acey), acenaphthene (Ace), fluorene (Flu), phenanthrene (Phe), anthracene (Ant),

\author{
Mr. Vu Duc Toan \\ Professor \\ Dept of Environment \\ Thuyloi University \\ Hanoi, Vietnam
}

\author{
Ms. Ngo Tra Mai \\ Researcher \\ Environmental Technology Center \\ Institute of Physics - Viet Nam Academy of Science and \\ Technology \\ Hanoi, Vietnam
}

fluoranthene (Flt), pyrene (Pyr), chrysene (Chr), benzo[a]anthracene (BaA), benzo[b]fluoranthene $(\mathrm{BbF})$, benzo[k]fluoranthene $(\mathrm{BkF})$, benzo[a]pyrene $(\mathrm{BaP})$, indeno [1,2,3-cd]pyrene (IcdP), dibenzo[a,h]anthracene (DahA), and benzo [g,h,i]pyrene (BghiP). There are a number of studies about these 16 PAHs in Vietnam; most of them focus on the air and dust environment, PAHs spread in the air and water, then deposit in the sediment of urban rivers; as a result, they continue to cause long-term impact on the environment. However, there is a little information on PAHs residue on mangrove soil in Vietnam.

Dong Rui area, the large land mangroves in Tien Yen district, Quang Ninh province, has high ecosystem diversity. To our knowledge, no data are available for the contamination of PAHs in this area as well as the toxicological risk assessment of PAHs residues on human. The objectives of this research are to assess occurence of selected PAHs in mangrove soil of Dong Rui area, Vietnam and their potential health risk assessment to fill this gap.

\section{EXPERIMENTAL}

The sampling was carried out in July 2016, during the dry season. Twelve representative sites were selected to investigate. Four surficial soil samples (marked from DR1 to DR4) were collected along BaChe River which is situated in the right side of Dong Rui' mangrove land. Meanwhile, eight surficial soil sample (marked from DR5 to DR12) were collected along VoiLon River and VoiBe River which is situated in the left side of Dong Rui' mangrove land (Fig.1). On the site DR4, DR5, DR6, several core soil samples were taken at the depth from 0 $5 \mathrm{~cm}, 5-10 \mathrm{~cm}, 10-15 \mathrm{~cm}, 15-20 \mathrm{~cm}$. The soil samples were collected with a stainless steel grab. All the samplers were immediately transferred to the laboratory. The samples were freeze-dried and homogenized. All the equipments used for sample collection, transportation, and preparation, were free from PAHs contamination. 
The PAHs concentration in the samples were determined using the method 8270D provided by US EPA with sightly modification [1]. Firstly, 10 grams of soil sample added with $10 \mathrm{~g}$ of anhydrous Na2SO4 and extract with $150 \mathrm{ml}$ mixture of dichloromethane and acetone (ratio $1: 1 \mathrm{v}$ ) for $24 \mathrm{~h}$ using a Soxhlet apparatus. Collect the extract, reduce volume to about $1 \mathrm{ml}$. Add $10 \mathrm{ml}$ of cyclohexane and then reduce to about $2 \mathrm{ml}$. Clean the extract through a column containing $10 \mathrm{~g}$ silicagel and $2 \mathrm{~g} \mathrm{Na} 2 \mathrm{SO} 4$ on top. Wash column with $25 \mathrm{ml}$ of pentane and discard. Elute the column with $25 \mathrm{ml}$ mixture of dichloromethane:pentane (ratio 4:6 in volume). Concentrate the extract to final volume $1 \mathrm{ml}$. The samples were analyzed by gas chromatography (GC, Agilent Technologies 7890A)/mass spectrometry (MS, Agilent Technologies 5975C). The average recoveries were $74.0-113.9 \%$. The method detection limits were $1 \mu \mathrm{g} \mathrm{kg}-1 \mathrm{dw}$ for all selected PAHs. Duplicates of soil samples were also performed and relative standard deviations were less than $10 \%$. All concentrations were calculated with respect to the dry weight $(\mathrm{dw})$ of soil samples. Mixture of PAHs standards have concentration of $10 \mathrm{ng} / \mathrm{ml}$ for each selected PAHs and were purchased from the Laboratories of Dr.Ehrenstorfer, Germany.

\section{DISCUSSION RESULT}

The PAHs concentrations in the surficial soil samples are shown in Table 1. In sampling sites along BaChe River, total concentrations of $\Sigma 16$ PAHs ranged from 522.1 to $1405.1 \mu \mathrm{g}$ $\mathrm{kg}-1 \mathrm{dw}$ (from DR1 to DR4, mean $881.7 \pm 392.1 \mu \mathrm{g} \mathrm{kg}-1 \mathrm{dw}$ ), while those along VoiLon River and VoiBe River ranged from 432.5 to $1873.4 \mu \mathrm{g} \mathrm{kg}-1 \mathrm{dw}$ (from DR5 to DR12, mean $928.4 \pm$ $523.2 \mu \mathrm{g} \mathrm{kg}-1 \mathrm{dw})$. It is observed that the highest value corresponded with site near estuary (site DR5, $1873.4 \mu \mathrm{g} \mathrm{kg}-1$ $\mathrm{dw}$ ) where interference between three rivers BaChe, VoiLon và VoiBe. PAHs were detected in all samples at the remarkable levels. The obtain results point out the wide occurrence of PAHs in the DongRui area. The concentrations of eight carcinogenic PAHs ( $\Sigma 8 \mathrm{C}-\mathrm{PAHs}$ : BaA, Chr, BbF, BkF, BaP, Ind, BghiP and DahA) range from 290.5 to $1058.3 \mu \mathrm{g} \mathrm{kg}-1$ (mean $527.7 \mu \mathrm{g} \mathrm{kg}-1$ ). The Pearson correlation coefficient between concentration of $\Sigma 16$ PAHs and $\Sigma 8 \mathrm{C}$-PAHs in soils of Dong Rui is 0.99 .

In Vietnam, no environmental standards have been established for PAHs in mangrove soil. When compared with other regions, the levels of PAHs in surficial soil of Dong Rui are higher than residues found in coastal soil of the Russian Arctic $(20-1380 \mu \mathrm{g} \mathrm{kg}-1 \mathrm{dw})$, surficial soils collected from reed wetland of Liaohe estuary, China $(235-374 \mu \mathrm{g} \mathrm{kg}-1 \mathrm{dw})$ [2,3]. Meanwhile, the levels of PAHs in Dong Rui are lower than residue in soils of the coastal and estuarine areas of the northern Bohai and Yellow Seas, China (66 - $920 \mu \mathrm{g} \mathrm{kg}-1 \mathrm{dw})$ as well as in soil collected from the Northern coast of the Persian Gulf, Iran (42.76 - $5596.42 \mu \mathrm{g} \mathrm{kg}-1 \mathrm{dw})$ [4,5].

In the core soil samples (Fig.2), total concentrations of $\Sigma 16$ PAHs ranged from 881.9 to $2236.1 \mu \mathrm{g} \mathrm{kg}-1 \mathrm{dw}$. The highest concentration is found at the depth from 5 to $10 \mathrm{~cm}$. This results indicated that residues of PAHs were not only found in surface soil, but also could penetrate deeper below the soil layers.

Significant PAHs residue raised question on the level of toxicity of PAHs in soil of Dong Rui. This requirement can be done by using toxic equivalence (TEQ) and ecological risk quotient (RQ). The TEQ value for each sample was obtained from the concentrations of PAHs using their toxic equivalency factors (TEFs) proposed by World Health Organization. TEQ of $\sum 8 \mathrm{C}$-PAHs and $\sum 16 \mathrm{PAHs}$ range from 51.8 to $309.2 \mu \mathrm{g}$ TEQ $\mathrm{kg}-1 \mathrm{dw}$ (mean $141.6 \pm 76.2 \mu \mathrm{g}$ TEQ $\mathrm{kg}-1 \mathrm{dw}$ ) and from 52.2 to $310.3 \mu \mathrm{g}$ TEQ $\mathrm{kg}-1 \mathrm{dw}$ (mean $142.1 \pm 76.4 \mu \mathrm{g}$ TEQ $\mathrm{kg}-1 \mathrm{dw})$, respectively. Eight carcinogenic PAHs have higher toxic potential than other PAHs indicators. Regarding to calculated TEQ values above, toxic effect of PAHs in soil of Dong Rui mainly contributed by $\sum 8 \mathrm{C}$-PAHs. The mean value of TEQ of $\sum 16$ PAHs in Dong Rui were higher than those in Liaohe estuary, China ( $0.1 \mu \mathrm{g}$ TEQ $\mathrm{kg}-1 \mathrm{dw})$, but lower than those in northern Bohai and Yellow Seas, China (32.6 $\mu \mathrm{g}$ TEQ $\mathrm{kg}-1 \mathrm{dw}$ ) and Northern coast of the Persian Gulf, Iran [3,4,5].

$\mathrm{RQ}$ is calculated by ratio of analyzed concentration and allowable concentration of selected PAHs in soil. The used allowable concentrations of PAHs are recommended by USEPA [6]. The values of RQ for individual PAHs are showed in table 2. Incase of $\mathrm{BaP}$, the values of RQ ranged from 1.98 to 13.71 whereas almost those of other RQ were less than 1 . Thus, individual PAHs might have little adverse effects on ecosystem. Due to the propensity of PAHs to accumulate in various compartments of environment, further evaluation of ecotoxicological should be undertaken as a high priority.

\section{CONCLUSION}

This work investigated the contamination status of PAHs in mangrove soil from Dong Rui area, Vietnam. Wide occurrence and high residue levels of PAHs has been found in the study area (from 432.5 to $1873.4 \mu \mathrm{g} \mathrm{kg}-1 \mathrm{dw}$ ). Compositions analyses show that PAHs with 4-6 ring compounds $(74.5 \%$ of the $\sum 16$ PAHs) were most dominant compounds in analyzed soil. The total TEQ values of $\sum 16 \mathrm{PAHs}$ in the soil samples from Dong Rui range from 52.2 to $310.3 \mu \mathrm{g}$ TEQ $\mathrm{kg}-1 \mathrm{dw}$. The calculation of RQ of individual PAHs show that PAHs might have little adverse effects on ecosystem. The main source of PAHs in Dong Rui are attributable to both petroleum conbustion and biomass burning.

\section{ACKNOWLEDGMENTS}

The authors would like to thank Thuyloi University, Trade Union University, Hanoi University of Science and Technology, Quatest 1 and Institute of Physics, Viet Nam Academy of Science and Technology for their support.

\section{REFERENCES}

[1] UNITED STATES ENVIRONMENTAL PROTECTION AGENCY Method 8270D Semivolatile organic compounds by gas chromatogaphy/ mass spectrometry ,U.S, 2008.

[2] ABAKUMOV E. V., TOMASHUNAS V. M., LODYGIN E. D. GABOV D. N., SOKOLOV V. T., KRYLENKO V. A., KIRSIDELI I. Yu. Polycyclic aromatic hydrocarbons in insular and coastal soils of the Russian Arctic. Eurasian. Soil. Sci. 48, (12), 1300, 2015.

[3] GUOLIANG L., YINHAI L., WEI Y., PENG P., XIAOMEI W. Source contributions of PAHs and toxicity in reed wetland soils of Liaohe estuary using a CMB-TEQ method. Sci. Total. Environ. 490, 199, 2014.

[4] JIAO.W., WANG T., KHIM JS., LUO W., HU W., NAILE JE., GIESY JP., LU Y. Polycyclic aromatic hydrocarbons in soils along the coastal and estuarine areas of the northern Bohai and Yellow Seas, China. Environ. Monit. Assess. 185, 8185, 2013.

[5] FATEMEH V., MOHAMAD P.Z., AHMAD Z.A. Polycyclic Aromatic Hydrocarbons Identification and Source Discrimination in Rural Soil of the Northern Persian Gulf Coast Environment Asia. 7, (1), 104, 2014. 
[6] UNITED STATES ENVIRONMENTAL PROTECTION AGENCY, Regional Screening Levels for Chemical Contaminants at Superfund Sites, 2016. Available from:

https://19january2017snapshot.epa.gov/sites/production/files/2016-

06/documents/master_sl_table_01run_may2016_0.pdf. Assessed on 7 July 2016.

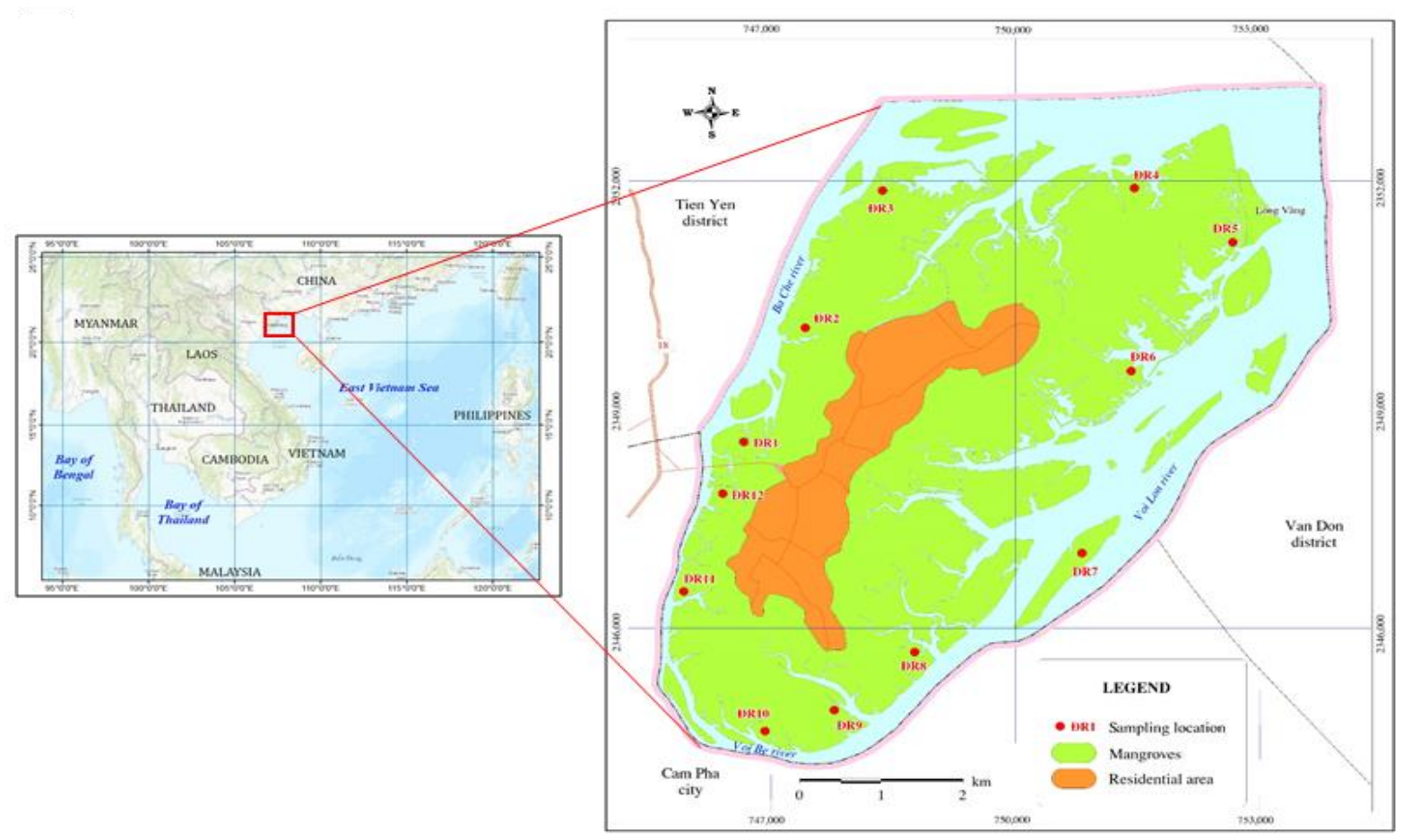

Fig. 1. Study area and sampling locations

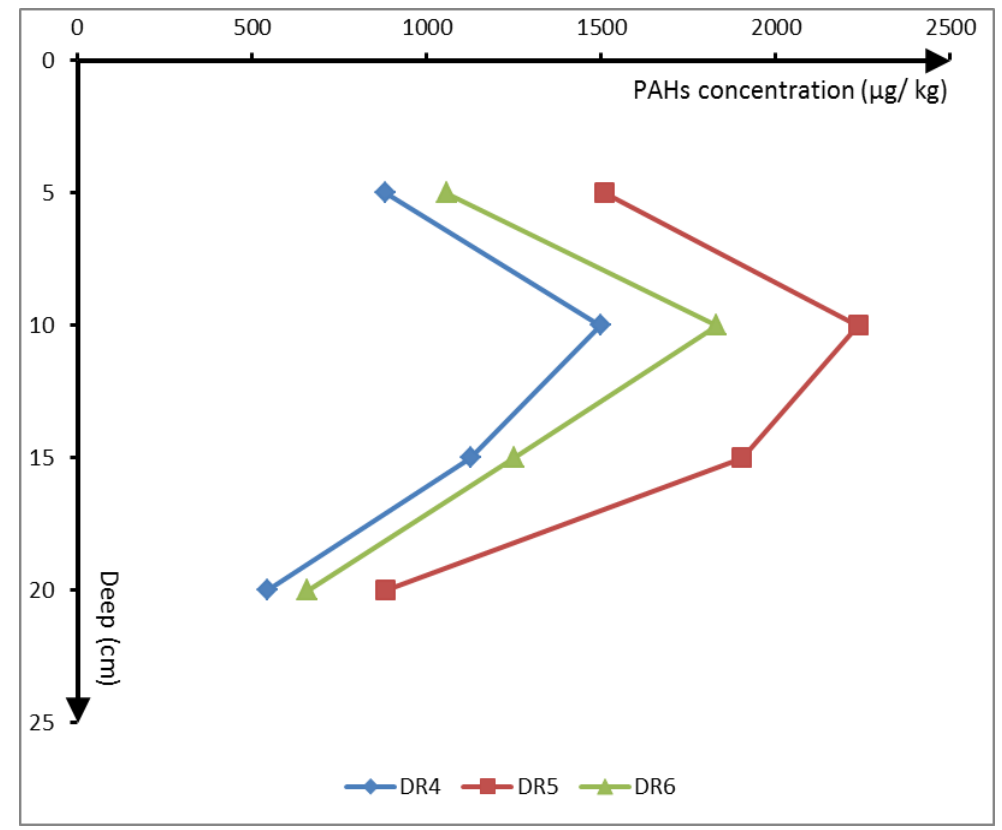

Fig. 2. Depth profile of PAHs concentration in soils of DongRui area. 
Table 1. TOC (\%) and concentrations of PAHs $\left(\mu \mathrm{g} \mathrm{kg}^{-1} \mathrm{dw}\right)$ in the soil samples

\begin{tabular}{|c|c|c|c|c|c|c|c|c|c|c|c|c|}
\hline \multirow{3}{*}{$\begin{array}{l}\text { Compound } \\
\text { Nap }\end{array}$} & \multirow{3}{*}{$\begin{array}{c}\text { TEF } \\
0.001\end{array}$} & \multicolumn{11}{|c|}{ Soil sample } \\
\hline & & \multicolumn{6}{|c|}{ Sampling sites along BaChe River } & \multicolumn{3}{|c|}{ Sampling sites along VoiLon } & \multicolumn{2}{|c|}{ VoiBe River } \\
\hline & & 9 & - & 72.5 & $(29.45$ & \pm & $29.30)^{(\mathrm{c})}$ & 8.2 & -64.6 & $(27.87$ & \pm & 22.07) \\
\hline Acy & 0.001 & 12.4 & - & 101.6 & $(47.55$ & \pm & 38.13) & 10.7 & $-\quad 128.9$ & $(53.85$ & \pm & $41.85)$ \\
\hline Ace & 0.001 & 18.5 & - & 53.4 & $(35.15$ & \pm & 17.72) & 11.4 & 57.5 & $(38.46$ & \pm & 18.48) \\
\hline Flu & 0.001 & 6.9 & - & 37.9 & $(22.4$ & \pm & 13.92) & 5.9 & $-\quad 118.3$ & $(30.97$ & \pm & 36.99) \\
\hline Phe & 0.001 & 30.4 & - & 103.5 & $(68.22$ & \pm & 29.9) & 15.8 & $-\quad 145.6$ & $(75.14$ & \pm & 48.94) \\
\hline Ant & 0.01 & 7.3 & - & 21.9 & (13.82 & \pm & $6.33)$ & 4.8 & 35.1 & (16.48 & \pm & $10.54)$ \\
\hline Py & 0.001 & 26.8 & - & 135.5 & $(67.85$ & \pm & 47.95) & 19.6 & - $\quad 125.6$ & $(62.66$ & \pm & 37.01) \\
\hline Flt & 0.001 & 21.3 & - & 210.7 & (95.5 & \pm & 81.41) & 21.7 & - $\quad 171.5$ & $(82.32$ & \pm & 59.98) \\
\hline $\mathrm{BaA}$ & 0.1 & 21.5 & - & 75.7 & $(53.8$ & \pm & 26.55) & 12.3 & - $\quad 165.4$ & (91.77 & \pm & $56.68)$ \\
\hline $\mathrm{Chr}$ & 0.01 & 25.7 & - & 73.6 & $(56.37$ & \pm & 21.26) & 24.8 & - 111.3 & $(61.82$ & \pm & $31.58)$ \\
\hline $\mathrm{BbF}$ & 0.1 & 22.7 & - & 150.7 & (79.7 & \pm & $56.65)$ & 23.4 & - $\quad 192.7$ & (77.15 & \pm & $60.47)$ \\
\hline $\mathrm{BkF}$ & 0.1 & 17.2 & - & 63.8 & (36.5 & \pm & 19.74) & 13.7 & $\begin{array}{l}-\quad 86.4 \\
\end{array}$ & (39.05 & \pm & 24.21) \\
\hline $\mathrm{BaP}$ & 1 & 42.3 & - & 162.6 & $(91.9$ & \pm & $54.58)$ & 31.7 & $-\quad 219.5$ & (102.32 & \pm & $60.45)$ \\
\hline Ind & 0.1 & 80.8 & - & 109.7 & (97.475 & \pm & 14.14) & 47.3 & - $\quad 163.7$ & $(90.75$ & \pm & 47.57) \\
\hline BghiP & 0.01 & 31.5 & - & 145.7 & (75.475 & \pm & 49.27) & 20.7 & $-\quad 112.5$ & (64.07 & \pm & $34.34)$ \\
\hline DahA & 1 & 5.8 & - & 14.6 & (10.525 & \pm & 3.62) & 6.3 & - $\quad 26.8$ & (13.67 & \pm & $6.67)$ \\
\hline$\Sigma_{8} \mathrm{C}-\mathrm{PAHs}{ }^{(\mathrm{a})}$ & & 293.7 & - & 712 & $(501.75$ & \pm & 178.53) & 290.5 & - 1058.3 & (540.62 & \pm & 280.13) \\
\hline$\Sigma_{16} \mathrm{PAHs}(\mathrm{b})$ & & 522.1 & - & 1405.1 & (881.7 & \pm & 392.06) & 432.5 & - 1873.4 & (928.38 & \pm & $523.23)$ \\
\hline
\end{tabular}

a: sum of 8 carcinogenic PAHs compounds (BaA. Chr. BbF. BkF. BaP. Ind. BghiP. DahA); b: sum of all 16 selected PAHs; c: Min - Max (mean \pm standard deviation).

Table 2. The values of RQ for individual PAHs in soil samples in Dong Rui area

\begin{tabular}{ccccc}
\hline & & \multicolumn{2}{c}{ RQ } \\
\cline { 2 - 5 } Compound & Allowable concentrations of PAHs & Min & Max & Mean \\
\hline Nap & 3.8 & $2.16 \times 10^{-3}$ & $1.9 \times 10^{-2}$ & $7.47 \times 10^{-3}$ \\
Acy & - (a) & - & - & - \\
Ace & 360 & $3.17 \times 10^{-5}$ & $1.6 \times 10^{-4}$ & $1.04 \times 10^{-4}$ \\
Flu & 240 & $2.46 \times 10^{-5}$ & $4.93 \times 10^{-4}$ & $1.17 \times 10^{-4}$ \\
Phe & - & - & - & - \\
Ant & 1800 & $2.67 \times 10^{-6}$ & $1.95 \times 10^{-5}$ & $8.66 \times 10^{-6}$ \\
Py & 180 & $1.09 \times 10^{-4}$ & $7.53 \times 10^{-4}$ & $3.58 \times 10^{-4}$ \\
Flt & 240 & $8.88 \times 10^{-5}$ & $8.78 \times 10^{-4}$ & $3.61 \times 10^{-4}$ \\
BaA & 0.16 & $7,68 \times 10^{-2}$ & 1.03 & 0.49 \\
Chr & 16 & $1.55 \times 10^{-3}$ & $6.95 \times 10^{-3}$ & $3.75 \times 10^{-3}$ \\
BbF & 0.16 & 0.14 & 1.2 & 0.49 \\
BkF & 1.6 & $8,56 \times 10^{-3}$ & 0.05 & $2.38 \times 10^{-2}$ \\
BaP & 0.016 & 1.98 & 13.71 & 6.17 \\
Ind & 0.16 & 0.29 & 1.02 & 0.58 \\
BghiP & - & - & - & - \\
DahA & 0.016 & 0.36 & 1.68 & 0.79 \\
\hline
\end{tabular}

a: no data 